\title{
Help through Digital Platforms in a Time of Distanced Connectivity- Application for Older Adults, People with Intellectual Disabilities and Individuals with Depression
}

\author{
Amberyce Ang \\ Singapore University of Social Sciences, Singapore \\ Correspondence should be addressed to Amberyce Ang, amberyce_xyee@yahoo.com.sg \\ Received: January 30, 2021; Accepted: February 15, 2021; Published Date: February 25, 2021
}

\begin{abstract}
Using the case study of an application "SGAssist", this study had demonstrated how vulnerable individuals can access help through digital platforms in a time of distanced connectivity. This study had collected information during the COVID-19 situation to understand how vulnerable individuals (particularly older adults, individuals with depression and people with intellectual disabilities) can connect with volunteers through the app and minimize the risk of social isolation. Information was collected through a questionnaire and interviews with 103 older adults, phone interviews with the founder of SGAssist, and the narratives collected from volunteers and beneficiaries of SGAssist. In view of the merits of using info-technology to seek help and mobilize recourses to the community through digital platforms, this study recommends increasing digital literacy for vulnerable individuals and their caregivers through training and guidelines on IT security.
\end{abstract}

\section{KEYWORDS}

Vulnerable individuals; Depression; COVID-19; Technology; App; Digital

\section{INTRODUCTION}

The COVID-19 pandemic has inevitably led to the practice of social distancing [1]. While social distancing has its merits in infectious disease control, it is also negatively associated with risks of social isolation [2]. For seniors, social isolation could result in negative emotional well-being and a lack of community support for their practical needs [3]. In order to mobilise timely assistance to vulnerable individuals during the COVID-19 pandemic, governments can turn to volunteers and community groups to fill gaps in public services [4].
Studies Nabatchi et al. [5], McGranahan [6], Ostrom E [7] described the direct involvement of citizens in voluntarily providing public services for their communities as "coproduction" and that volunteering is an essential component for co-production [5] to be effective.

In the current era of digitalization, digital platforms such as mobile apps can play a key role in recruiting volunteers, in soliciting help, and in activating resources to be released efficiently to vulnerable individuals. The use of mobile

Citation: Amberyce Ang, Help through Digital Platforms in a Time of Distanced Connectivity-Application for Older Adults, People with Intellectual Disabilities and Individuals with Depression. Psychiatry 1(1): 18-24. 
apps can even scale-up the co-production process by reaching vulnerable individuals nation-wide [8].

The concept of "distanced connectivity" through online and digital platforms, then becomes more critical in lending help to vulnerable individuals during the COVID19 situation [9] described the COVID-19 "Connectivity Paradox" as a conflicting risk or a harm continuum resulting from social distancing. Smith et al. [9] study suggested for partnerships between clinical and community-based groups to provide support and to engage seniors.

In light of this situation, this paper examines how help can be rendered through digital platforms for vulnerable individuals, particularly during a time of social distancing, due to the COVID-19 outbreak. Vulnerable individuals in this study refer to older adults, people with intellectual disabilities (PWID) and individuals with depression. SGAssist is a digital platform based in Singapore that connects volunteers and people who are finding help in real time using artificial intelligence technology and mobile apps.

\section{The Context of Singapore -A Smart Nation}

Singapore is a small nation of approximately 725.7 square kilometers in size (data.gov.sg, "Total Land Area"). According to the Department of Statistics Singapore, we have a population size of 5.69 million (as of June 2020) and a ratio of 4.3 adults aged between 20 years to 64 years old, to every older adult aged above 65 years. As such, the country's relatively small size and ageing population makes it ideal to examine the effectiveness of digital support. The dense population in a small area meant that there is a significant demand for help from seniors and that help can be relatively easy to mobilize as compared to larger countries with sparse populations.

In addition, Singapore is a smart nation, with high smartphone usage to connect with others through mobile applications and online social networking platforms
(Statistica Research Department, Age Distribution of Mobile Internet Users on Social Networking Singapore 2019). Familiarity with smartphone usage meant that accessing help and providing help though digital platforms would not be challenging for most Singaporeans.

\section{The Need to Strengthen Community Support in Ageing Populations}

As a modern country in Asia, the Confucian value of filial piety is not unheard of in Singapore. However, the meaning and expression of filial piety could evolve over time. According to studies [10-13], filial piety may oblige adult children to provide care for parents. However, this obligation could also lead to caregiver burden and depressive symptoms, particularly if the adult children are also managing multiple roles and responsibilities e.g. fulltime work and young children.

As another layer of the social security net, the Singapore government practices the "many helping hands" approach, [14] in which Singapore's public sector partners, voluntary welfare organizations and community groups to effectively deliver a range of social services and assistance [15]. These partnerships are an important aspect of Singapore's social institutions, in which it is believed that the family is the first tier of support, followed by the community and the government. While the "many helping hands" approach has helped Singaporeans to foster greater self-reliance, it presents challenges to its sustainability in the evolving context of Singapore's demographics [16]. As families in Singapore are smaller than earlier generations, adult children might find it more stressful to cope with the caregiving demands of their elderly parents.

These pressures may lead to an adaptation of the concept of filial piety among the younger generation in Singapore [17] and possibly expressed in new forms of "outsourced" filial piety, such as paid informal or paid formal care. In comparison, [18] found that adult children in Hong Kong rely on paid caregiving in the form of hiring foreign domestic helpers to care for their parents. Foreign 
Domestic Helpers provide caregiving support in place of working adults children, thereby allowing the elderly parents to age-in-place; a more desirable option than institutional care.

Against this backdrop of strained resources on adult children in the Singapore context and social distancing in the COVID-19 situation, accessing and utilizing community resources through digital platforms become pertinent. The research questions put forth were a) How can help be rendered to vulnerable individuals during social distancing? And b) How can social isolation be reduced for vulnerable individuals?

\section{METHOD}

In-depth interviews were conducted in person with 103 older adults between the ages of 55 years to 72 years in Singapore. To determine the level of socio-emotional resources, participants were asked about their level of loneliness, their self-rated perception on the importance of social media in their lives, their level of satisfaction in close friendships and familial relations, for example. Their responses were rated on a five-point Likert scale ranging from 1 (being the most negative) to 5 (being the most positive).

Interview questions expounded on the survey questions that had used Likert-scale ratings, by asking the participants to share the rationale behind their ratings. Coding and thematic analysis $[19,20]$ was used to interpret the experiences shared through the interviews.

Data collection aimed to understand older adult's need for social capital and their perception of social media for the purpose of digital connectivity. Data collection was approved by the Institutional Review Board of Singapore, University of Social Sciences. Phone interviews were also conducted with the founder of SGAssist to understand apps usage for vulnerable individuals and their caregivers. SGAssist had also contributed the narratives of their volunteers, some of which were posted on SGAssist's social media platforms.

\section{DISCUSSION}

Distanced Connectivity for Vulnerable Individuals

According to the SGAssist founder, the SGAssist app was primarily used by the caregivers of vulnerable individuals to meet essential needs. Caregivers of vulnerable individuals had enlisted the help of volunteers through the SGAssist app for grocery shopping, for bringing the vulnerable individuals to see a doctor, for collecting medicine from the polyclinic, to find missing older adults with dementia and even for befriending those who were suffering from depression. An example was a volunteersponsored outing to the zoo for a beneficiary. Volunteers assisted to escort the beneficiary and the family for the outing, which was a meaningful way to reduce social isolation. Possibly as a manifestation of the negative effects of social distancing, SGAssist noticed the increased number of lonely and depressed individuals and caregivers who are stressed, seeking for help during the COVID-19 situation.

\section{SGAssist}

"Prior to COVID-19, we get requests from the organizations, agencies, etc. but since the outbreak of COVID-19, we get a lot more requests from individuals. Most of the requests were to meet their daily needs. We have also received requests such as helping families find missing person with dementia and even befriending those who are lonely and depressed. The good thing about using the app for individuals is that the response rate for volunteers is very fast"

At the point of the interviews, SGAssist was in the midst of running pilot tests on "Telecare", a service in which volunteers contact PWID or their caregivers daily to check in on them and render support where applicable. Through Telecare, volunteers will be enlisted to assist PWID and if paid assistance is required, SGAssist will compare and 
recommend the most economical option to the PWID or their caregivers.

\section{Overcoming Barriers to Digital Literacy for Older Adults through Training and Guidelines on it Security}

Echoing the benefits of finding help through digital platforms, other studies [21] have reported on the positive effects of technology in empowering older adults to be more independent. Technology enables older adults to find information, get help, and communicate efficiently, particularly during the COVID-19 situation. Despite the benefits of using social apps for help, our data suggested apprehension in using social media and information technology to connect with others, thereby hindering vulnerable individuals' access to a potential pool of community resources from digital platforms.

Similar to our data findings, other research [22-24] also noted that the common barriers to older adults' usage of technology are attitudinal barriers, cognitive barriers and privacy concerns [25]. Common examples of these barriers are the older adults' attitudes that technology is not relevant to them, technology is difficult to use and technology may cause them to risk falling prey to scams or expose their personal information.

Participants in this study also resisted using social media to engage with others as they found it dangerous to do so and prioritized protecting their own privacy. A 66-years old female retiree who was formerly a teacher said: "I don't share anything in Facebook. I feel like people are intruding into my privacy, but I use it to look at other people's Facebook (laughs)".

A 65-years old female retiree who was formerly a sales and procurement officer said that my children told me not to share any information on Facebook, so I only use it to read Newsfeed, know what are the new things that are going on, look at friends's profiles for example. I don't chat with anyone.
Generally, older adults who resist technology are likely lacking in confidence in their ability to use technology efficiently and a lack of confidence in how the benefits of technology can outweigh the challenges and risks in using it [22-24]. These barriers widen the digital gap between the relatively more tech-savvy younger generation and the older generation.

These barriers can be overcome by training older adults on IT and app usage. SGAssist app connects vulnerable individuals or people who require help. One of SGAssist "initiatives was the launch of their "digital literacy program" in which SGAssist assigned volunteers to train older adults on IT and app usage. To allay fears of cybersecurity threats, online phishing and scams, guidelines should be implemented [26]. Highlighted the need for multi-directional guidelines as current guidelines focus on one-way transfer of information."

\section{Increasing Socio-Emotional Resources and Functional} Help from Digital Platforms can Counter the Risk of Social Isolation for Vulnerable Individuals

Interestingly, the use of social media was not viewed by participants in this study to be a good substitute for personal interactions. Participants in this study had given an average score of 2.6 points on a five-point Likert scale when asked to rate how significant social media was in their lives. Social media was viewed as a form of entertainment and as a source of information instead. Participants described their use of social media to read news, to get information that is trending, to read posts and to watch videos for info-entertainment.

However, the use of digital platforms such as the SGAssist app allows vulnerable individuals to access the dual benefits of practical help and also socio-emotional resources derived from the volunteers' help. As a result, vulnerable groups could increase their level of socioemotional resources and potentially countering the negative states of loneliness and depression. 
A female beneficiary of SGAssist who was battling with depression and suicide recounted that her "Life was miserable... depression... threatening of suicide daily for more than two years. [SGAssist] comforts me... helps me to go through my... problems"

Female volunteer shared that the help she offered was not only in practice, but she had the opportunity to offer emotional support for troubled vulnerable individuals "I helped senior $\mathrm{X}$ to shift mattress and chatted with her, she shared about her frustrations and worries about not having a job because of COVID-19".

Caregiver of a vulnerable individual who found help through SGAssist during the social distancing situation expressed his appreciations "Thanks. Reason how I got to know your app was through the papers I think during the height of the COVID-19 season. I think your app actually addresses the need of ad hoc request which might just be more common, especially (when) our community median age gets higher".

\section{CONCLUSION}

This study has largely focused on the digitalization of help for vulnerable individuals. Apart from increasing the digital literacy of older adults, this study recommends that understanding the motivations of volunteers is crucial in securing a sustainable pool of volunteers as a resource for vulnerable individuals to access community resources and aids. Volunteers can be motivated through various means, such as expressions of gratitude, [27] by fostering a sense of community [28] or even using a functional approach to meet the practical needs of volunteers [29].

On the academic aspect of this study, it is recommended that future studies use sharper measurements to examine the social capital yield from the use of digital help, and in particular, the associations between mental health issues and access to help received from digital platforms and the association between depression and help received through the digital platforms or through volunteer befrienders. Future research should delve deeper and collect larger data to understand the effectiveness of digital literacy programs in increasing the enlistment of help through digital platforms. It is also recommended for an evaluation on "Telecare" to be conducted, so as to enhance care and help delivered through "Telecare".

\section{DATA AVAILABILITY}

A request for data can be made and subjected to the approval of SUSS' IRB.

\section{CONFLICT OF INTEREST}

No funding was received for this study and the author has no conflict of interest to declare.

\section{REFERENCES}

1. Wilder-Smith A, Freedman DO (2020) Isolation, quarantine, social distancing and community containment: Pivotal role for old-style public health measures in the novel coronavirus (2019-nCoV) outbreak. Journal of Travel Medicine 27(2): taaa020.

2. Gupta R, Dhamija RK (2020) Covid-19: Social distancing or social isolation?. BMJ: 369.

3. Nicholson NR (2012) A review of social isolation: An important but underassessed condition in older adults. The journal of Primary Prevention 33(2-3): 137-152.

4. Miao Q, Schwarz S, Schwarz G (2021) Responding to COVID-19: Community volunteerism and coproduction in China. World Development 137: 105128.

5. Nabatchi T, Sancino A, Sicilia M (2017) Varieties of participation in public services: The who, when, and what of coproduction. Public Administration Review 77(5): 766-776. 
http://www.tridhascholars.org | June -2021

6. McGranahan G (2015) Realizing the right to sanitation in deprived urban communities: Meeting the challenges of collective action, coproduction, affordability, and housing tenure. World Development 68: 242-253.

7. Ostrom E (1996) Crossing the great divide: Coproduction, synergy, and development. World Development 24(6): 10731087.

8. Lember V, Brandsen T, Tõnurist P (2019) The potential impacts of digital technologies on co-production and co-creation. Public Management Review 21(11): 1665-1686.

9. Smith ML, Steinman LE, Casey EA (2020) Combatting social isolation among older adults in a time of physical distancing: The COVID-19 social connectivity paradox. Frontiers in Public Health 8: 403.

10. Lieber E, Nihira K, Mink IT (2004) Filial piety, modernization, and the challenges of raising children for Chinese immigrants: Quantitative and Qualitative Evidence. Ethos 32(3): 324-347.

11. Lai DW (2010) Filial piety, caregiving appraisal, and caregiving burden. Research on Aging 32(2): 200-223.

12. Dong X, Xu Y (2016) Filial piety among global Chinese adult children: A systematic review. Research \& Review: Journal of Social Science 2(1): 46-55.

13. Li M, Dong X (2018) The association between filial piety and depressive symptoms among US Chinese older adults. Gerontology and Geriatric Medicine 4: 2333721418778167.

14. Rozario PA, Rosetti AL (2012)“Many Helping Hands": A review and analysis of long-term care policies, programs, and practices in Singapore. Journal of Gerontological Social Work 55(7): 641-658.

15. https://www.psd.gov.sg/heartofpublicservice/our-institutions/

16. Ang BL (2017) Sinapore's many helping hands, civil society and the State in Singapore. World Scientific: $133-152$.

17. Muyskens K (2020) Will confucian values help or hinder the crisis of elder care in modern Singapore?. Asian Bioethics Review 12: 117-134.

18. Ho KH, Chiang VC, Leung D, et al. (2018) When foreign domestic helpers care for and about older people in their homes: I am a maid or a friend. Global Qualitative Nursing Research 5: 2333393617753906.

19. Schoonenboom J, Johnson RB (2017) How to construct a mixed methods research design. KZfSS Kölner Zeitschrift Für Soziologie und Sozialpsychologie 69(2): 107-131.

20. Boyatzis RE (1998) Transforming qualitative information: Thematic analysis and code development. Sage.

21. Xie B (2003) Older adults, computers, and the Internet: Future directions. Gerontechnology 2(4): 289-305.

22. Vaportzis E, Giatsi Clausen M, Gow AJ (2017) Older adults perceptions of technology and barriers to interacting with tablet computers: A focus group study. Frontiers in Psychology 8: 1687.

23. Charness N, Boot WR (2009) Aging and information technology use: Potential and barriers. Current Directions in Psychological Science 18(5): 253-258.

24. Berkowsky RW, Sharit J, Czaja SJ (2017) Factors predicting decisions about technology adoption among older adults. Innovation in Aging 1(3): igy002.

25. Czaja SJ, Charness N, Fisk AD, et al. (2006) Factors predicting the use of technology: Findings from the Center for research and education on aging and technology enhancement (CREATE). Psychology and Aging 21(2): 333.

26. Jaeger PT, Xie B (2009) Developing online community accessibility guidelines for persons with disabilities and older adults. Journal of Disability Policy Studies 20(1): 55-63.

27. Naqshbandi KZ, Liu CF, Taylor S, et al. (2020) "I am most grateful." using gratitude to improve the sense of relatedness and motivation for online volunteerism. International Journal of Human-Computer Interaction 36(14): 1325-1341. 
http://www.tridhascholars.org | June -2021

28. Stukas AA, Hoye R, Nicholson M, et al. (2016) Motivations to volunteer and their associations with volunteers' wellbeing. Nonprofit and Voluntary Sector Quarterly 45(1): 112-132.

29. Snyder M, Clary EG, Stukas AA (2000) The functional approach to volunteerism. Why we evaluate: Functions of Attitudes 365: 393. 